\title{
LA EFECTIVIDAD DE LOS DERECHOS Y LIBERTADES CONTENIDAS EN LAS NORMAS INTERNACIONALES DEL DERECHO DEL TRABAJO Y DE LA SEGURIDAD SOCIAL. UNA VISIÓN COMPARADA LATINOAMERICANA: LA LIBERTAD SINDICAL
}

\author{
THE EFFECTIVENESS OF THE RIGHTS AND FREEDOMS \\ CONTAINED ON INTERNATIONAL STANDARDS OF LABOUR \\ LAW AND SOCIAL SECURITY. A COMPARATIVE LATIN \\ AMERICAN VISION: THE FREEDOM OF ASSOCIATION
}

\author{
Valente Quintana* \\ Escuela Libre de Derecho, México \\ José AlFonso ApAricio** \\ Universidad Autónoma de México, México \\ “...Un acto de hombres libres, lo repetiremos nuevamente, \\ que no puede ser limitado ni entorpecido por las autoridades públicas, \\ porque la libertad no es un don del Estado, sino que \\ le fue impuesta por el pueblo en la Constitución"1 \\ Mario de la Cueva
}

\section{INTRODUCCIÓN}

El maestro Mario de la Cueva define a la libertad sindical como:

"Un deber negativo del Estado de dos facetas, no estorbar la libre sindicación y no obstruccionar la lucha del trabajo contra el capital; un deber positivo al capital, consignado magníficamente en el artículo 387 de la Ley: "el patrono que emplee trabajadores miembros de un sindicato, tendrá obligación de celebrar con éste, cuando lo solicite, un contrato colectivo"; y un deber positivo del Estado: obligar a los empresarios a la celebración de dicho contrato" (De la Cueva 1979, p. 287).

Profesor de la Escuela.Libre de Derecho, México. Coordinador académico de postgrado. Contacto: valentequintana@eld.edu.mx Profesor de la Universidad Autónoma de México, Departamento de Investigación de Derecho Social.

De LA CuEva (1979) p. 287. 
Para el popular líder sindical mexicano Vicente Lombardo Toledano, la libertad sindical era un nuevo camino creado por el Estado para la emancipación integral del proletariado "y un derecho limitado a la defensa de sus intereses materiales, tratándose del capitalismo" (Lombardo 1926 , p. 25$)^{2}$.

Como es bien conocido, la Declaración francesa (1789) no garantizó la libertad general de asociación; lo cierto es que el pueblo francés aceptó, primero, por las presiones de la clase trabajadora, la libertad sindical y no fue sino años más tarde cuando reconoció la libertad general de asociación, por lo que puede decirse que la libertad sindical pudo vivir sin libertad general ${ }^{3}$.

A principios del siglo XX, los delitos de coalición y de huelga comenzarían a ser desterrados de la legislación penal en la mayoría de los países. En el caso de México, correspondió al famoso Código Penal de Martínez de Castro la triste misión de penalizar la coalición y la huelga. Tiempo después, quedaría preservada, en definitiva, la libertad de asociación en el texto de la Constitución de $1917^{4}$.

Como deslinde inicial queremos señalar que la tendencia dominante en la doctrina, tanto de los autores internacionales, como son García Oviedo, Bayón Chacón y Pérez Botija, Ojeda Avilés, Barrionuevo Peña, Gallart Folch. Como de los autores mexicanos: Euquerio Guerrero, Santos Azuela, Néstor De Buen ${ }^{5}$, por mencionar algunos; tienen una postura igualadora del concepto "libertad sindical" con el de "libertad de asociación", posición de la cual nos apartamos ya que consideramos que aun cuando son conceptos que se interconectan no son lo mismo. Por un lado la libertad sindical tiene la característica de que es definida en función de la persona moral, en tanto la libertad de asociación puede darse en dos ámbitos: en el individual, que implica la libertad que tiene una persona física (patrón o trabajador) de pertenecer, y por razón obvia o consecuente también de no pertenecer o dejar de pertenecer a un sindicato; y en el ámbito colectivo, que implica la libertad, ya no de un individuo sino de la persona moral o jurídico colectiva de derecho social -que es el sindicato-, para pertenecer, no pertenecer o dejar de pertenecer a una federación o confederación. Cuestión última que empata con una vertiente de la "libertad sindical", pero no entendemos así a la libertad de asociación que tienen las personas físicas.

Deslinde anterior que para efectos del trabajo dejaremos enunciado pero no haremos mayor tratamiento por la naturaleza del trabajo, al mismo tiempo que reconocemos la interdependencia, no así la igualación de conceptos, que existe entre ambos significados. Tal como lo señala el jurista brasileño Mozart V. Russomano, el cual concibe a la libertad sindical como figura triangular, si ésta se pudiera representar geométricamente: "Sindicación libre, autonomía sindical y pluralidad sindical", aunando lo señalado por el Dr. Bouzas en cuanto a su valoración de los elementos mínimos que deben existir para que haya libertad sindical: plena autonomía de las organizaciones sindicales; auténtica representatividad de los trabajadores; democracia interna de las organizaciones sindicales ${ }^{7}$,que -agregaríamos- tiene como consecuencia o síntoma la transparencia sindical (tanto endógena como exógena).

Por último, consideramos oportuno advertir que la exposición que haremos del nivel de protección en México a la «libertad sindical» obedece al contexto en que se ha gestado la orga-

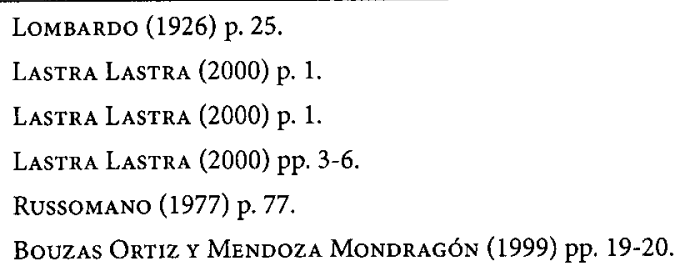


Valente Quintana, José Alfonso Aparicio / La efectividad de los derechos y libertades contenidas en las Normas Internacionales del Derecho del Trabajo y de la Seguridad Social. Una visibn comparada latinoamericana: la libertad sindical

nización obrera en México, dentro del fenómeno del denominado corporativismo ${ }^{8}$, dependiente y sumisa con el Estado y la empresa, frente a una incipiente organización sindical comúnmente denominada independiente y auténtica ${ }^{9}$, que no siempre escapa a las prácticas corporativas.

\section{ANÁLISIS NORMATIVO DE LA LIBERTAD SINDICAL EN MÉXICO}

Es preciso reflexionar que los derechos laborales son una expresión más de derechos humanos $^{10}$. Derechos que para el caso mexicano constituyen derecho doméstico ya sea de fuente nacional o internacional ${ }^{11}$. Siendo así, hemos tenido a bien considerar el tratamiento de este apartado desde tres ángulos: 1. Legislación internacional, en que México es parte; 2 . Legislación nacional; y 3. Consideraciones adicionales, sobre las normativas anteriores. Todo ello con referencial al tema de «libertad sindical».

\subsection{INTERNACIONAL}

Consideramos importante establecer, en primer lugar, que México es parte de la Organización Internacional del Trabajo (en adelante OIT) desde 1931, así como de diversos instrumentos que tienen como objetivo consagrar la protección de los derechos de los trabajadores como parte de los derechos humanos, y que nuestro país ha ratificado con el fin de integrarlos al derecho nacional, que por tanto subsiste la obligación de adecuar paulatinamente nuestra legislación al contenido de estos instrumentos de derecho internacional en materia de relaciones laborales. Instrumentos entre los que podemos destacar, para el interés del tema que nos ocupa (la libertad sindical), los siguientes:

- La Constitución de la Organización Internacional del Trabajo, la "Declaración relativa a los fines y objetivos de la OIT" y la "Declaración de Filadelfia".

- Convenio número 87 de la Organización Internacional del Trabajo.

- La Declaración Universal de Derechos Humanos.

- La Carta de la Organización de Estados Americanos.

- La Convención Americana sobre Derechos Humanos.

\subsubsection{Organización Internacional del Trabajo (OIT)}

Ahora bien, estimamos conveniente -para abordaren el presente texto el tratamiento del primer instrumento normativo de origen internacional- analizar previamente y de manera sucinta la naturaleza de la OIT, la cual tiene por objeto emitir convenios en materia de trabajo, así como vigilar su debida aplicación entre los países que tienen a bien ratificarlos. La OIT es un organismo especializado perteneciente a la Organización de las Naciones Unidas, y nace en 1919 como uno de los resultados más importantes del Tratado de Versalles al término de la primera guerra mundial, siendo producto de la necesidad de abolir varias prácticas que violentaban no solo derechos laborales del hombre, entre otros derechos humanos.

\footnotetext{
Bouzas Ortiz y Mendoza Mondragón (1999) p. 30.

Bouzas Ortiz y Mendoza Mondragón (1999) p. 83.

10 Sánchez-Castañeda (2008).

11 Fix-Zamudio (2006).
} 
Valente Quintana, José Alfonso Aparicio / La efectividad de los derechos y libertades contenidas en Las Normas Internacionales del Derecho del Trabajo y de la Seguridad Social. Una visión comparada latinoamericana: la libertad sindical

La OIT tiene como actividad principal emitir Normas Internacionales de Trabajo, mismas que marcan las condiciones mínimas en derechos laborales fundamentales como: "libertad sindical", derecho de sindicación, derecho de negociación colectiva, abolición del trabajo forzoso, igualdad de oportunidades y de trato, así como otras normas por las que se regulan condiciones que abarcan todas las cuestiones relacionadas con el trabajo. Dichas normas se dividen en; convenios, que son tratados internacionales sujetos a ratificación por los estados miembros; y recomendaciones, que sin ser instrumentos vinculantes, habitualmente versan sobre los mismos temas que los convenios, teniendo como objetivo orientar la política y la acción de cada estado miembro.

Es claro percibir que si la OIT tiene a bien procurar un sano equilibrio internacional entre los factores, capital y trabajo, así como darle ciertas garantías a los derechos laborales, cierto es también que no puede sola como organismo velar por estos intereses a nivel global, cada secretaría o ministerio del trabajo, así como cada empresa tienen que impulsar sus propias políticas laborales en su país, e inculcar una cultura laboral para un beneficio bilateral entre los factores de la producción.

Hasta el momento en que redactamos el presente escrito la OIT ha emitido 189 convenios que son sujetos a ratificación por los estados miembros, y dentro de estos convenios existen ocho que son declarados por esta organización como fundamentales y tratan tópicos que son considerados como principios y derechos fundamentales en el trabajo, como la libertad de asociación y la "libertad sindical". La OIT desde su constitución, y en la Declaración de Filadelfia en sus párrafos I y III, reconoce que es parte de su labor fomentar entre los países miembros de esta organización la "Libertad de asociación", así como la "Negociación colectiva". México como país miembro tiene el compromiso de tomar las medidas necesarias para empatar su legislación nacional en materia de relaciones de trabajo con los principios rectores de la OIT, entre ellos desde luego el derecho de la "Libertad sindical".

Con el fin de darle mayor sentido a estos párrafos, es de mencionar que la: "Declaración de la OIT relativa a los principios y derechos fundamentales en el trabajo y su seguimiento" establece que todos los miembros de la OIT que hubieren ratificado o no un convenio tienen el alto compromiso que se deriva de la propia pertenencia en cuanto al respeto y promoción de los principios relativos a los derechos fundamentales objeto de sus convenios ${ }^{12}$.

\subsubsection{Convenio 87 OIT}

Para seguir por el camino normativo que ha impulsado la OIT, y como consecuencia lógica de nuestro trabajo, cabe señalar que los convenios de mayor trascendencia en materia de "libertad sindical" son: el Convenio 87, relativo a la "Libertad sindical, y la protección del derecho de sindicación", ratificado por nuestro país ${ }^{13}$; y el Convenio número 98 relativo al "Derecho de sindicación y de negociación colectiva", el cual no se encuentra ratificado por nuestro país.

El Convenio 87 de la OIT establece que las organizaciones de trabajadores y empleadores tienen derecho a redactar sus estatutos, elegir a sus representantes, así como organizar su administración.

Por otro lado, menciona que las autoridades públicas deberán de abstenerse de toda intervención que tienda a limitar este derecho o a entorpecer su ejercicio legal. Establece que las organizaciones de trabajadores y empleadores tienen libre derecho a constituir federaciones y

\footnotetext{
12 BEAUdONNET (2009).

13 Ratificado por México el 1 de abril de 1950.
} 
confederaciones, así como a afiliarse a ellas. La adquisición de la personalidad jurídica por estas organizaciones no puede estar sujeta a condiciones cuya naturaleza limite la aplicación de estas disposiciones.

Convenio que a nuestra consideración contrasta en algunas partes con la legislación nacional y más aún: con la práctica cotidiana. Cuestiones que en los siguientes apartados habremos de evidenciar.

\subsubsection{Comité de Libertad Sindical OIT}

Es importante mencionar que la OIT creó el Comité de Libertad Sindical con el propósito de estudiar las protestas en relación con las violaciones de libertad sindical presentadas por organizaciones de trabajadores y de empleadores, este Comité depende del Consejo de Administración y se compone colegiadamente por un presidente del comité, así como por tres representes, uno del gobierno, otro del capital y otro del trabajo, respectivamente.

Si al someter las controversias ante el Comité, este decide que en efecto existe una violación a los principios de «libertad sindical», emitirá un informe a través del Consejo de Administración y formulará recomendaciones. Posteriormente se solicitará a los gobiernos que informen sobre la observación de sus recomendaciones.

Es importante saber que el Comité es competente aún frente a Estados que no hayan ratificado los convenios de «libertad sindical», en la medida en que el procedimiento de queja en materia de «libertad sindical» se base en la Constitución de la OIT, aceptada por todos los estados miembros, y esto cobra relevancia ya que, como mencionamos anteriormente, México no tiene ratificado aún el Convenio número 97, relativo al "Derecho de sindicación y negociación colectiva", como tampoco el Convenio 135, relativo a la "Protección y facilidades que deben otorgarse a los representantes de los trabajadores en la empresa", pero por el simple hecho de la membrecía a la OIT se ve obligado a respetar dichos derecho establecidos en los principios de dicha Organización.

Las quejas en materia de libertad sindical son presentadas contra los gobiernos de los Estados, es por ello que el Comité dirige las recomendaciones al Gobierno del país correspondiente, ahora, si bien el Comité no es un Tribunal Internacional, sí puede analizar la actuación del Poder Judicial para evaluar el respeto a los principios de libertad sindical, y de esta manera pronunciarse sobre las consecuencias de ciertas decisiones de tribunales nacionales.

Luego entonces, es importante resaltar que la competencia de este Comité no dependerá de que sean agotadas las instancias jurisdiccionales nacionales, por lo que cuando el objeto de la queja es tramitado internamente en cada país, el Comité puede tomar la decisión de exponer los principios que le sean aplicables a cada caso en específico con el propósito de que los tribunales que conozcan del asunto puedan tomar en cuentas estas observaciones.

El Comité de Libertad Sindical deberá de cuidar el cumplimiento de los derechos que componen este concepto, como lo son el derecho de constituir organizaciones sin autorización previa, así como el derecho de afiliarse a estas, el derecho del libre funcionamiento de las organizaciones, así como de redactar sus propios estatutos y reglamentos, el derecho de elegir a quienes serán sus representantes y de organizar la manera en que se van a administrar, el derecho de constituir federaciones y confederaciones, y por supuesto el derecho de huelga.

Por lo anterior es que nos atrevemos a afirmar que no es una mera coincidencia que nuestra legislación laboral tenga en su estructura gran parte de los principios fundamentales por los que vela la OIT. 
Valente Quintana, José Alfonso Aparicio / La efectividad de los derechos y libertades contenidas en las Normas Internacionales del Derecho del Trabajo y de la Seguridad Social. Una visión comparada latinoamericana: la libertad sindical

\subsection{NACIONAL}

Tal como ha señalado en diversas ocasiones el prestigioso jurista mexicano Héctor FixZamudio "la protección fundamental de los derechos humanos es la interna, porque radica en los estados nacionales la carga fundamental de proteger los derechos de fuente internacional" (FixZamudio) y a nuestra consideración, como hemos insistido, esa suerte siguen los derechos laborales. La libertad sindical se encuentra protegida en la Constitución Política de los Estados Unidos Mexicanos (en adelante CPEUM); y regulada en: la Ley Federal del Trabajo (en adelante LFT), la Ley Federal de los Trabajadores al Servicio del Estado (en adelante LFTSE); así como delineada por una, aún escasa, jurisprudencia emitida por nuestros tribunales federales.

\subsubsection{Constitución}

Podemos derivar la protección y reconocimiento del derecho de libertad sindical en los siguientes artículos de la CPEUM:

a) Artículo 9. Reconoce el derecho de asociación de la siguiente manera:

"No se podrá coartar el derecho de asociarse o reunirse pacíficamente con cualquier objeto lícito; pero solamente los ciudadanos de la República podrán hacerlo para tomar parte en los asuntos políticos del país. Ninguna reunión armada, tiene derecho de deliberar.

No se considerará ilegal, y no podrá ser disuelta una asamblea o reunión que tenga por objeto hacer una petición o presentar una protesta por algún acto a una autoridad, si no se profieren injurias contra ésta, ni se hiciere uso de violencias o amenazas para intimidarla u obligarla a resolver en el sentido que se desee".

Derecho que en genérico incluye "cualquier objeto lícito", envolviendo al de asociación sindical. Aunque este artículo constitucional había sido poco abordado por los tratadistas mexicanos por encontrarse dentro de un capítulo que se denominaba "Garantías Individuales" y por tanto se tenía la concepción de que era la expresión de un derecho individual, sin tomar en cuenta que tal derecho es en esencia siempre el mismo: la voluntad individual de varios sujetos para asociarse de manera de manera colectiva. Tal como lo expresó Burgoa: “También la libertad sindical encuentra su apoyo en el artículo 9 constitucional, como derecho público subjetivo de obreros y patrones, oponible al Estado y sus autoridades" (Burgos 1984, p. 37).

b) Artículo 123. En particular (de manera expresa) reconoce el derecho de libertad sindical, en su fracción XVI de su apartado "A", que a continuación citamos: "XVI. Tanto los obreros como los empresarios tendrán derecho para coaligarse en defensa de sus respectivos intereses, formando sindicatos, asociaciones profesionales, etc."

Fracción que se encuentra sin modificación alguna desde nuestro constituyente originario en 1917, que inauguró el constitucionalismo social en el mundo y así también la protección constitucional de tan importante derecho, anticipándose a la OIT.

El mismo artículo 123 contiene un segundo apartado " $\mathrm{B}$ ", el cual regula las relaciones laborales de los trabajadores del Gobierno del Distrito Federal y de los Poderes de la Unión, que en su fracción X establece: "Los trabajadores tendrán el derecho de asociarse para la defensa de sus intereses comunes. Podrán, asimismo, hacer uso del derecho de huelga previo el cumplimiento de los 
requisitos que determine la ley, respecto de una o varias dependencias de los Poderes Públicos, cuando se violen de manera general y sistemática los derechos que este artículo les consagra".

\subsubsection{Leyes}

a) Ley Federal del Trabajo (LFT):

La LFT tiene un "Título Séptimo" que da tratamiento a las relaciones colectivas de trabajo y en su "Capítulo 11 " regula lo referente a los sindicatos, a lo largo de 29 artículos, de los cuales sólo señalaremos (citaremos textualmente si es necesario) las cuestiones que nos parecen ilustran el modelo de protección o desprotección -según se analice- de la libertad sindical.

El derecho de Libertad Sindical específicamente se regula en el artículo 357, que a la letra dice: "Los trabajadores y los patrones tienen el derecho de constituir sindicatos, sin necesidad de autorización previa. Cualquier injerencia indebida será sancionada en los términos que disponga la Ley".

Cuestión anterior que nos merece dos consideraciones. La primera, que las sanciones a las "injerencias indebidas", que por cierto fue materia de la reciente reforma a nuestra LFT, tal como lo señalan los tratadistas Sánchez-Castañeda y Reynoso Castillo podrían llevar a concluir que indirectamente se está reconociendo la existencia de "injerencias debidas", así como no queda claro a quien está dirigido este mensaje de prohibición: si a las autoridades públicas que algo tengan que ver con el nacimiento y vida sindicales, o bien, al público en general ${ }^{14}$. La segunda consideración es referente al señalamiento que dichas injerencias serán sancionadas en términos de la Ley, cuando ésta no se ocupa en ninguna parte del tema ${ }^{15}$.

En el subsiguiente artículo 358 se prohíbe lo que se conoce como la "cláusula de exclusión"16, redactado de la siguiente manera: "A nadie se puede obligar a formar parte de un sindicado o a no formar parte de él. Cualquier estipulación que establezca multa convencional en caso de separación del sindicato o que desvirtúe de algún modo la disposición contenida en el párrafo anterior, se tendrá por no puesta.".

En nuestra opinión subsiste una antinomia del citado artículo 258 con referencia al artículo 395 que permite la existencia de una cláusula de exclusión por admisión en el Contrato Colectivo de Trabajo, que a la letra dice:

"En el contrato colectivo, podrá establecerse que el patrón admitirá exclusivamente como trabajadores a quienes sean miembros del sindicato contratante. Esta cláusula y cualesquiera otras que establezcan privilegios en su favor, no podrán aplicarse en perjuicio de los trabajadores que no formen parte del sindicato y que ya presten sus servicios en la empresa o establecimiento con anterioridad a la fecha en que el sindicato solicite la celebración o revisión del contrato colectivo y la inclusión en él de la cláusula de exclusión.".

Continúa la regulación sindical en el siguiente artículo (359), estableciendo el reconocimiento a lo que consideramos la expresión natural de la autonomía que da la libertad sindical: "Los sindicatos tienen derecho a redactar sus estatutos y reglamentos, elegir libremente a sus representantes, organizar su administración y sus actividades y formular su programa de acción.".

\footnotetext{
14 Sánchez-Castañeda y Reynoso Castillo (2013) pp. 66.

15 Sánchez-Castañeda y Reynoso Castillo (2013) pp. 66.

16 Sánchez-Castañeda (2002) pp. 105-106.
} 
El artículo 360 establece las clasificaciones de sindicatos de trabajadores (gremiales, de empresa, industria, nacionales de industria, de oficios varios). El art. 361 establece las clasificaciones de los sindicatos de patrones (locales y nacionales). El artículo 362 establece que "pueden formar parte de los sindicatos los mayores de catorce años"17.

El artículo 363 prohíbe el ingreso de los trabajadores de confianza a los sindicados formados por trabajadores que no lo son. El artículo 364 establece el mínimo de trabajadores necesarios para poder constituir un sindicato. Cuestiones anteriores que no se establecen constitucionalmente y por tanto, en nuestra opinión, no debiese distinguir la ley.

Con referencia al registro de los sindicatos, se da tratamientos a partir del artículo 364 Bis hasta el artículo 370 .

El artículo 364 Bis establece: «En el registro de los sindicatos se deberán observar los principios de legalidad, transparencia, certeza, gratuidad, inmediatez, imparcialidad y respeto a la libertad, autonomía, equidad y democracia sindical ${ }^{\prime 18}$. Principios que nos parecen importantes para la salvaguarda de la libertad sindical.

El artículo 365 establece el deber de los sindicatos de registrarse ante la autoridad competente.

El artículo 365 Bis. establece la obligación de las autoridades de hacer pública la información del registro de los sindicatos ${ }^{19}$.

El Artículo $366^{20}$ estipula la negativa del registro, para los casos en que el sindicato no se proponga la finalidad de llevar a cabo el estudio, mejoramiento y defensa de los intereses de sus miembros; si no se constituyó con el número de miembros fijado en el artículo 364 y si no exhibe los documentos que se piden para el registro (copia autorizada del acta de asamblea constitutiva; lista con las generales de sus miembros; copia de los estatutos y copia del acta de la asamblea en que hubieren elegido a la directiva). Además se establece que:

"Si la autoridad ante la que se presentó la solicitud de registro, no resuelve dentro de un término de sesenta días naturales, los solicitantes podrán requerirla para que dicte resolución, y si no lo hace dentro de los tres días siguientes a la presentación de la solicitud, se tendrá por hecho el registro para todos los efectos legales, quedando obligada la autoridad, dentro de los tres días siguientes, a expedir la constancia respectiva”.

Precepto que tiende a hacer efectiva la libertad sindical ya que transcurridos los términos de sesenta días naturales para resolver sobre el registro y los tres del requerimiento para que las autoridades dicten la resolución, ipso jure, automáticamente, se tiene por registrado el sindicato y desde ese momento goza de personalidad jurídica. Las autoridades deberán expedir la constancia respectiva y en caso de no hacerlo incurren en responsabilidad, pudiendo suplirse la constancia con otros medios de prueba. La personalidad en este caso se podrá comprobar con las copias selladas de la solicitud y requerimientos respectivos. Cuando las autoridades nieguen el registro

\footnotetext{
17 Edad laboral que establecía la CPEUM en su artículo 123 apartado A, fracción IIl, pero que por razón de una reforma acontecida el año 2014, ahora establece como edad mínima laboral 15 años, con el fin de estar acorde a los estándares internacionales. Cfr. DOF de fecha 17/06/14.

18 Artículo adicionado en la reciente reforma de 2012. Cfr. DOF de fecha 30/11/12.

19 Artículo adicionado en la reciente reforma de 2012. Cfr. DOF de fecha 30/11/12.

20 Bouzas Ortiz y Mendoza Mondragón (1999) pp. 19-20.
} 
Valente Quintana, José Alfonso Aparicio / La efectividad de los derechos y libertades contenidas en las Normas Internacionales del Derecho del Trabajo y de la Seguridad Social. Una visión comparada latinoamericana: La libertad sindical

del sindicato, los que aparezcan como representantes de éste podrán ocurrir en juicio de amparo indirecto ante el Juez de Distrito competente como dispone la Ley de Amparo ${ }^{21}$.

El artículo 368 establece que el registro del sindicato y de su directiva produce efectos ante todas las autoridades.

Lo anterior, tal como lo ha dicho Néstor De Buen: conduce a la conclusión de que el registro tiene simplemente el valor de ser un instrumento de información, lo mismo ocurre con los registros de propiedad o de sociedades civiles o mercantiles. Esas personas morales se constituyen desde antes, de la misma manera que la propiedad se transfiere mediante el acto celebrado entre las partes interesadas, por lo que el registro tiene solamente una función publicitaria. No hay razón alguna para que respecto a los sindicatos se convierta al registro en un acto constitutivo o reconocedor de la personalidad de sus dirigentes, a lo que se agrega el requisito mal intencionado de la toma de nota previsto en la fracción IV del artículo 692 de la $\mathrm{LFT}^{22}$.Fracción IV del artículo 692 de la LFT, que a continuación citamos: "Los representantes de los sindicatos acreditarán su personalidad con la certificación que les extienda la autoridad registradora correspondiente, de haber quedado inscrita la directiva del sindicato. También podrán comparecer por conducto de apoderado legal, quien en todos los casos deberá ser abogado, licenciado en derecho o pasante". Certificación que en los hechos es un mecanismo discrecional de la autoridad, al negar el registro o negar la expedición del oficio de "toma de nota", inventando cualquier irregularidad respecto a la documentación exhibida, lo que a la autoridad registradora la "convierte automáticamente en un órgano jurisdiccional con una supuesta capacidad de calificación de la que evidentemente carece" (De Buen 2011, p. 48) y con ello violenta la condición de abstenerse de toda intervención que entorpezca el derecho de "libertad sindical" consagrado en el artículo $3^{\circ}$ del Convenio 87 de la OIT y el propio artículo 357 de la LFT.

El artículo 369 establece las razones por las que podrá cancelarse el registro: disolución o dejar de tener los requisitos legales.

El artículo 371 establece un listado de contenidos que obliga a tener a los sindicatos en sus estatutos:

"Los estatutos de los sindicatos contendrán: I. Denominación que le distinga de los demás; II. Domicilio; III. Objeto; IV. Duración. Faltando esta disposición se entenderá constituido el sindicato por tiempo indeterminado; $V$. Condiciones de admisión de miembros; VI. Obligaciones y derechos de los asociados; VII. Motivos y procedimientos de expulsión y correcciones disciplinarias. En los casos de expulsión se observarán las normas siguientes:

a) La asamblea de trabajadores se reunirá para el solo efecto de conocer de la expulsión.

b) Cuando se trate de sindicatos integrados por secciones, el procedimiento de expulsión se llevará a cabo ante la asamblea de la sección correspondiente, pero el acuerdo de expulsión deberá someterse a la decisión de los trabajadores de cada una de las secciones que integren el sindicato.

c) El trabajador afectado será oído en defensa, de conformidad con las disposiciones contenidas en los estatutos.

d) La asamblea conocerá de las pruebas que sirvan de base al procedimiento y de las que ofrezca el afectado.

e) Los trabajadores no podrán hacerse representar ni emitir su voto por escrito.

21 Trueba URbina y Trueba Barrera (2008) pp. 177.

22 De BUEN (2011) p. 41. 
f) La expulsión deberá ser aprobada por mayoría de las dos terceras partes del total de los miembros del sindicato.

g) La expulsión sólo podrá decretarse por los casos expresamente consignados en los estatutos, debidamente comprobados y exactamente aplicables al caso;

VIII. Forma de convocar a asamblea, época de celebración de las ordinarias y quórum requerido para sesionar. En el caso de que la directiva no convoque oportunamente a las asambleas previstas en los estatutos, los trabajadores que representen el treinta y tres por ciento del total de los miembros del sindicato o de la sección, por lo menos, podrán solicitar de la directiva que convoque a la asamblea, y si no lo hace dentro de un término de diez días, podrán los solicitantes hacer la convocatoria, en cuyo caso, para que la asamblea pueda sesionar y adoptar resoluciones, se requiere que concurran las dos terceras partes del total de los miembros del sindicato o de la sección; VIII Las resoluciones deberán adoptarse por el cincuenta y uno por ciento del total de los miembros del sindicato o de la sección, por lo menos; IX. Procedimiento para la elección de la directiva y número de miembros, salvaguardando el libre ejercicio del voto con las modalidades que acuerde la asamblea general; de votación indirecta y secreta o votación directa y secreta; X. Periodo de duración de la directiva; XI. Normas para la administración, adquisición y disposición de los bienes, patrimonio del sindicato; XII. Forma de pago y monto de las cuotas sindicales; XIII. Época de presentación de cuentas y sanciones a sus directivos en caso de incumplimiento. Para tales efectos, se deberán establecer instancias y procedimientos internos que aseguren la resolución de controversias entre los agremiados, con motivo de la gestión de los fondos sindicales. XIV. Normas para la liquidación del patrimonio sindical; $y X V$. Las demás normas que apruebe la asamblea".

Cuestión que merece el comentario de los ya citados especialistas laborales, Sánchez-Castañeda y Reynoso Castillo, al señalar la fracción $\mathrm{IX}^{23}$ como una intención pertinente de favorecer a la democracia sindical, pero con una argumentación inadecuada, al considerar que limita la libertad sindical, atentando contra la libertad de determinar libremente las condiciones de elección de sus dirigentes sindicales, al detallar legislativamente el modo de elección sindical ${ }^{24}$.

$\mathrm{El}$ artículo 372 establece quienes no podrán formar parte de la directiva: los trabajadores menores de 16 años y los extranjeros.

El artículo $373^{25}$ solo se refiere a la obligación de la directiva de los sindicatos de rendir cuentas a la asamblea, por lo menos cada seis meses. Señalando que cualquier trabajador tendrá el derecho de solicitar información a su directiva, sin embargo es un derecho que se reconoce pero no se protege ${ }^{26}$.

El artículo 374 les da el atributo de personas morales y con capacidad propia a los sindicatos. Lo cual sería suficiente para poder comparecer a juicio y no el requisito impuesto por el artículo 692, referido anteriormente.

El artículo 375 establece: "Los sindicatos representan a sus miembros en la defensa de los derechos individuales que les correspondan, sin perjuicio del derecho de los trabajadores para obrar o intervenir directamente, cesando entonces, a petición del trabajador, la intervención del sindicato".

\footnotetext{
23 Bouzas Ortiz y Mendoza Mondragón (1999) pp. 19-20.

24 Sánchez-Castañeda y Reynoso Castullo (2013) pp.68.

25 Bouzas Ortiz y Mendoza Mondragón (1999) pp. 19-20.

26 Lastra lastra (2000) p. 71.
} 
El artículo 376 establece que la representación se ejercerá por medio de su secretario general o persona que designe su directiva, salvo disposición especial de sus estatutos. Planteando: « La representación del sindicato se ejercerá por su secretario general o por la persona que designe su directiva, salvo disposición especial de los estatutos. Los miembros de la directiva que sean separados por el patrón o que se separen por causa imputable a éste, continuarán ejerciendo sus funciones salvo lo que dispongan los estatutos".

Situación que a nuestro juicio, respeta la libertad sindical al establecer la independencia del patrón sobre la vida interna, por lo que hace a este respecto.

El artículo 377 estipula las obligaciones de los sindicatos, a saber: "Son obligaciones de los sindicatos: I. Proporcionar los informes que les soliciten las autoridades del trabajo, siempre que se refieran exclusivamente a su actuación como sindicatos; II. Comunicar a la autoridad ante la que estén registrados, dentro de un término de diez dias, los cambios de su directiva y las modificaciones de los estatutos, acompañando por duplicado copia autorizada de las actas respectivas; y III. Informar a la misma autoridad cada tres meses, por lo menos, de las altas y bajas de sus miembros. Las obligaciones a que se refiere este artículo podrán ser cumplidas a través de medios electrónicos, en los términos que determinen las autoridades correspondientes".

De comentario obligado es la fracción l, que se encuentra redactada de manera generalísima con respecto la información que "le solicite la autoridad sobre su actuación como sindicato" pudiendo con ello prestarse a la injerencia indebida del Estado a la vida interna del sindicato y atentando contra la "libertad sindical".

En el artículo 378 se establecen las prohibiciones a los sindicatos: intervenir en actos religiosos y ejercer actos de comercio con ánimo de lucro.

Finalmente, el artículo 381 estipula la posibilidad que tienen los sindicatos de formar federaciones y confederaciones. Cuestión que es expresión clara de la libertad de asociación que tiene el sindicato, es decir: libertad expresada de manera colectiva y no en su vertiente individual. En tanto el artículo 382 establece que los miembros podrán retirarse de ellas en cualquier tiempo aunque exista pacto en contrario, cuestión que vuelve a expresar el respeto a la aludida libertad de asociación, tanto en su carácter positivo como negativo ${ }^{27}$.

b) Ley Federal de los Trabajadores al Servicio del Estado (LFTSE)

Como es posible advertir desde la Constitución mexicana el tratamiento diferenciado a los trabajadores burocráticos (establecido en el artículo 123 apartado ' $\mathrm{B}^{\prime 28}$, citado páginas atrás), se agudiza en la ley reglamentaria-la LFTSE- que a nuestro juicio reduce múltiples derechos laborales, entre ellos -sin temor a equivocarnos-, muy claramente el derecho de libertad sindical. Veamos:

El artículo 67. Define a los sindicatos de la siguiente manera: "Los sindicatos son las asociaciones de trabajadores que laboran en una misma dependencia, constituidas para el estudio, mejoramiento $y$ defensa de sus intereses comunes".

Siendo evidente, y desde nuestra comprensión razonable, que se excluya de la organización sindical a los patrones, que en el caso es el propio Estado.

El artículo 68 establece lo que se le ha conocido en la doctrina mexicana como la 'sindicación única', que tiene la siguiente redacción: «En cada dependencia sólo habrá un sindicato. En caso de que concurran varios grupos de trabajadores que pretendan ese derecho, el Tribunal Federal

\footnotetext{
$27 \quad$ LOMBARDo (1926) p. 25.

28 Después de un largo transcurrir se logró reconocer que el Estado tenía el carácter de patrón y por tal se creó en 1960 un apartado B en el artículo 123 constitucional, pero con un menguado derecho laboral en contraste al apartado A del mismo artículo.
} 
Valente Quintana, José Alfonso Aparicio / La efectividad de los derechos y libertades contenidas en las Normas Internacionales del Derecho del Trabajo y de la Seguridad Social. Una visión comparada latinoamericana: la libertad sindical

de Conciliación y Arbitraje otorgará el reconocimiento al mayoritario". Numeral que ha sido declarado inconstitucional por la jurisprudencia 43/99, que en el siguiente apartado de este texto citaremos.

El artículo 69 establece la imposibilidad de dejar de formar parte del sindicato, una vez ingresado. Con una flagrante violación a la libertad de asociación en su aspecto negativo: "Todos los trabajadores tienen derecho a formar parte del sindicato correspondiente, pero una vez que soliciten y obtengan su ingreso, no podrán dejar de formar parte de él, salvo que fueren expulsados".

El artículo 70 al Igual que en la LFT, se excluye la posibilidad de que los trabajadores de confianza formen parte de los sindicatos de trabajadores que no son de confianza: "Los trabajadores de confianza no podrán formar parte de los sindicatos. Cuando los trabajadores sindicalizados desempeñen un puesto de confianza, quedarán en suspenso todas sus obligaciones y derechos sindicales".

El artículo 71 establece la precondición de la no existencia de un sindicato previo con mayor número de miembros, para que se pueda constituir un sindicato:"Para que se constituya un sindicato, se requiere que lo formen veinte trabajadores o más, y que no exista dentro de la dependencia otra agrupación sindical que cuente con mayor número de miembros".

Cuestión que sería muy distinta si el criterio de mayoría se tomara en cuenta para ser titular de un Contrato Colectivo de Trabajo, como lo establece la LFT, pero no una precondición de mayoría que supedite la existencia sindical, que claramente violenta la multicitada "libertad sindical". El artículo 72 señala el tema del registro sindical de la siguiente manera:

"Los sindicatos serán registrados por el Tribunal Federal de Conciliación y Arbitraje, a cuyo efecto remitirán a éste, por duplicado, los siguientes documentos. I.- El acta de la asamblea constitutiva o copia de ella autorizada por la directiva de la agrupación; II.- Los estatutos del sindicato. III.- El acta de la sesión en que se haya designado la directiva o copia autorizada de aquella, y IV.- Una lista de los miembros de que se componga el sindicato, con expresión de nombres, de cada uno, estado civil, edad, empleo que desempeña, sueldo que perciba y relación pormenorizada de sus antecedentes como trabajador.

El Tribunal Federal de Conciliación y Arbitraje, al recibir la solicitud de registro, comprobará por los medios que estime más prácticos y eficaces, que no existe otra asociación sindical dentro de la dependencia de que se trate y que la peticionaria cuenta con la mayoría de los trabajadores de esa unidad, para proceder, en su caso, al registro".

Artículo que en su último párrafo nos merece el mismo comentario que en los artículos pasados referentes a la sindicación única y que como hemos dicho ha sido declarada inconstitucional.

El artículo 73 al igual que en el artículo anterior sigue dando tratamiento al tema del registro sindical y se vuelve a repetir la sindicación única como prerequisito, que merecen los mismos comentarios dichos al respecto: "El registro de un sindicato se cancelará por disolución del mismo o cuando se registre diversa agrupación sindical que fuere mayoritaria. La solicitud de cancelación podrá hacerse por persona interesada y el Tribunal, en los casos de conflicto entre dos organizaciones que pretendan ser mayoritarias, ordenará desde luego el recuento correspondiente y resolverá de plano".

El artículo 74 establece las condiciones de expulsión de un miembro del sindicato: "Los trabajadores que por su conducta ofalta de solidaridad fueren expulsados de un sindicato, perderán. 
por ese solo hecho todos los derechos sindicales que esta ley concede. La expulsión sólo podrá votarse por la mayoría de los miembros del sindicato respectivo o con la aprobación de las dos terceras partes de los delegados sindicales a sus congresos o convenciones nacionales y previa defensa del acusado. La expulsión deberá ser comprendida en la orden del día".

Cuestión que apreciamos podría representar una vulneración a la autonomía y con ello a la libertad sindical, por el solo hecho de establecer en la ley las condiciones para expulsar a un miembro del sindicato.

El Artículo 75 establece que: "Queda prohibido todo acto de reelección dentro de los sindicatos". Prohibición que aunque nos parezca benéfica en cuanto hace que la perpetración del liderazgo sindical no se vuelva un lastre para los propios agremiados y genere rotación en sus líderes, no creemos que se justifique al entender que eso es una decisión que única y exclusivamente le corresponderá a sus agremiados decidir al interior y no por una imposición legislativa que coarte la libertad de aquellos. Además de valorar que en el caso mexicano aún con esta prohibición ha habido quienes han permanecido inamovibles en la dirigencia, creando puestos "perpetuos" que no están supeditados a elección y por tanto tampoco a su reelección ${ }^{29}$.

El artículo 76 señala que dentro del via crucis que observamos en estos artículos, sorprende una luz dentro del túnel obscuro de protección a la "libertad de asociación" establecido en este artículo, con la prohibición de la cláusula de exclusión: "El Estado no podrá aceptar, en ningún caso, la cláusula de exclusión".

El artículo 77 establece las obligaciones para los sindicatos:

"Son obligaciones de los sindicatos: I.- Proporcionar los informes que en cumplimiento de esta Ley, solicite el Tribunal Federal de Conciliación y Arbitraje; II.- Comunicar al Tribunal Federal de Conciliación y Arbitraje, dentro de los diez días siguientes a cada elección, los cambios que ocurrieren en su directiva o en su comité ejecutivo, las altas y bajas de sus miembros y las modificaciones que sufran los Estatutos; III.- Facilitar la labor del Tribunal Federal de Conciliación y Arbitraje, en los conflictos que se ventilen ante el mismo, ya sea del Sindicato o de sus miembros, proporcionándole la cooperación que le solicite, y IV.-Patrocinar y representar a sus miembros ante las autoridades y ante el Tribunal Federal de Conciliación y Arbitraje cuando les fuere solicitado".

Obligación de la fracción IV que claramente es contrastante con la establecida en la LFT en que el patrocinio y representación del sindicato a sus miembros ante las autoridades, se da ipso iure. En tanto en esta LFTSE, solamente cuando los miembros así lo soliciten.

El artículo 78 estipula la posibilidad de "adhesión" no así de formación a una única federación: "Los sindicatos podrán adherirse a la Federación de Sindicatos de Trabajadores al Servicio del Estado, única central reconocida por el Estado.". Redacción más que obvia en su violación a la libertad de asociación que tienen los sindicatos.

El artículo 79 establece las prohibiciones a los sindicatos: «Queda prohibido a los sindicatos: I.- Hacer propaganda de carácter religioso; II.- Ejercer la función de comerciantes, con fines de lucro. III.- Usar la violencia con los trabajadores libres para obligarlos a que se sindicalicen; IV.- Fomentar actos delictuosos contra personas o propiedades, $y$ V.-Adherirse a organizaciones o centrales obreras o campesinas".

29 Tal es el caso de la ex lideresa de uno de los sindicatos más fuertes en México, el Sindicato Nacional de Trabajadores de la Educación (SNTE), con un puesto de Presidenta Vitalicia. 
Valente Quintana, José Alfonso Aparicio / La efectividad de los derechos y libertades contenidas en las Normas Internacionales del Derecho del Trabajo y de la Seguridad Social. Una visión comparada latinoamericana: la libertad sindical

Prohibición establecida en la fracción III, nos parece que es tutelar de la libertad de asociación que tiene cada individuo, caso contrario con la fracción $\mathrm{V}$ que restringe la libertad de asociación de los sindicatos.

El artículo 83 establece la cancelación del registro: "En los casos de violación a lo dispuesto en el Artículo 79, el Tribunal Federal de Conciliación y Arbitraje determinará la cancelación del registro de la directiva o del registro del sindicato, según corresponda".

Cuestión que consideramos impertinente por lo que hace a la fracción $\mathrm{V}$ del artículo 79 , antes mencionado, así como intromisorio a la vida interna del sindicato en cuanto a cancelar el registro de una directiva libremente elegida por sus agremiados y que por tal solo corresponde a ellos removerlos.

El artículo 84 establece la regulación de la Federación de Sindicatos de la siguiente manera: "La Federación de Sindicatos de Trabajadores al Servicio del Estado se regirá por sus estatutos y, en lo conducente, por las disposiciones relativas a los sindicatos que señala esta Ley. En ningún caso podrá decretarse la expulsión de un sindicato del seno de la Federación".

Párrafo segundo que nos parece igualmente violatorio de la libertad sindical porque la expulsión es un tema que debería corresponder decidir a los miembros de dicha federación.

El artículo 86. Establece el origen del pago a los directivos y empleados del sindicato: "Las remuneraciones que se paguen a los directivos y empleados de los sindicatos $y$, en general, los gastos que origine el funcionamiento de éstos, serán a cargo de su presupuesto, cubierto en todo caso por los miembros del sindicato de que se trate".

Cuestión anterior de suma importancia, ya que la Constitución ${ }^{30}$ y la muy reciente Ley General de Transparencia ha puesto a los sindicatos como "sujetos obligados" de la rendición de cuentas, pero solo por lo que hace al uso de recursos públicos, es decir que las cuotas sindicales con las que subsidian las remuneraciones referidas en su sindicato no son a nuestro juicio susceptibles de ser consideradas como información pública de interés general.

Por último, es necesario denunciar que en México, en materia burocrática, se ha hecho nugatorio el derecho de negociación colectiva al no existir la posibilidad de un Contrato Colectivo de Trabajo que establezca las condiciones negociadas en materia colectiva entre el patrón y los trabajadores, correspondiendo sólo al patrón el asignar las condiciones en que se prestará el trabajo, siendo totalmente unilateral ${ }^{31}$.

El artículo 87 establece que: "Las Condiciones Generales de Trabajo se fijarán por el Titular de la Dependencia respectiva, tomando en cuenta la opinión del Sindicato correspondiente a solicitud de éste, se revisarán cada tres años".

Sumado a lo anterior, también se encuentra igualmente negado el ejercicio de huelga, pero esto más grave desde la Constitución ${ }^{32}$ : "Los trabajadores tendrán el derecho de asociarse para la defensa de sus intereses comunes. Podrán, asimismo, hacer uso del derecho de huelga previo el cumplimiento de los requisitos que determine la ley, respecto de una o varias dependencias de los Poderes Públicos, cuando se violen de manera general y sistemática los derechos que este artículo les consagra".

Violación "general y sistemática" que es prácticamente imposible que se dé y que por tanto la huelga nunca ha sido un instrumento de solución para los llamados trabajadores burocráticos.

\footnotetext{
30 En su artículo 6.

31 Razón por la cual México no ha firmado el Convenio $\mathrm{N}^{\circ} 154$, de 11 de agosto de 1983, sobre Negociación Colectiva.

32 Cfr. Fracción "X", apartado "B", del artículo 123 de la CPEUM.
} 
Negando así la vida sindical en su plenitud con la cancelación a la trilogía colectiva (sindicación, contratación colectiva y huelga) $)^{33}$.

\subsection{JURISPRUDENCIA}

La línea que nuestros tribunales federales han seguido, encargados específicamente de restituir el orden constitucional violado, con relación a la libertad sindical ha sido escasa. Aún no existe un gran número de tesis jurisprudenciales, ni tesis aisladas al respecto, considerando que los temas que vincula la libertad sindical son diversos y extensos. Para efectos de ilustrar la línea de criterios seguidos en diversos aspectos que tocan la libertad sindical, hemos realizado una selección, que a nuestra consideración podría dar luz del grado de avance, ya no solo normativo propiamente -como si puede inferirse de los apartados anteriores- sino también jurisprudencial, que viene a cuestionar o dejar firme el universo de normas relacionadas con la libertad sindical.

\subsubsection{Toma de nota de directiva sindical. Es aplicable analógicamente el procedimiento previsto por el artículo 366, último párrafo, de la Ley Federal del Trabajo}

Si bien no existe norma expresa que establezca el procedimiento para la toma de nota establecida en el artículo 377, fracción II, de la Ley Federal del Trabajo, conforme al artículo 17 del mismo ordenamiento, ante la falta de disposición expresa en la ley, se considerarán, entre otros supuestos, sus disposiciones que regulen casos semejantes. Por tal motivo, y como el registro de un sindicato y la toma de nota de cambio de directiva son situaciones semejantes, por ser cuestiones referentes al reconocimiento de la personalidad de aquél, diferenciándose únicamente por un aspecto temporal, se concluye que a la toma de nota le es aplicable por analogía el procedimiento previsto en el artículo 366, último párrafo, de la propia Ley, que prevé los plazos y consecuencias legales a seguir para el registro de un sindicato, pues el registro y la toma de nota de cambio de directiva sindical implican la actualización de situaciones de hecho y de derecho que la autoridad encargada debe verificar para salvaguardar la garantía de seguridad jurídica ${ }^{34}$.

\subsubsection{Sindicatos. El artículo 371, fracción IX, de la Ley Federal del Trabajo, al prever que} sus estatutos contendrán el procedimiento para la elección de su directiva y que ésta podrá realizarse mediante votación indirecta, no viola los principios de autonomía y libertad sindicales (Legislación vigente a partir de 1 de diciembre de 2012)

La Suprema Corte de Justicia de la Nación ha considerado que el sistema de vida democrático reconocido constitucionalmente trasciende a la organización sindical, de manera que la libertad de sindicación (en sus distintas vertientes), no es un impedimento absoluto para que las autoridades verifiquen que los estatutos y la organización de los sindicatos se ajusten a las exigencias democráticas derivadas de la Constitución Política de los Estados Unidos Mexicanos. De acuerdo con lo anterior, el artículo 371, fracción IX, de la Ley Federal del Trabajo, al prever que los estatutos de los sindicatos contendrán el procedimiento para la elección de la directiva,

\footnotetext{
33 Razón por la que México no ha firmado y ratificado los Convenios 98 y 154 de la OIT, referentes a la sindicación y la negociación colectiva, respectivamente.

34 Tesis Jurisprudencial consultable en: http://200.38.163.178/sjfsist/Paginas/DetalleGeneralV2.aspx?id=161163\&Clase $=$ Deta lleTesisBL
} 
Valente Quintana, José Alfonso Aparicio / La efectividad de los derechos y libertades contenidas en las Normas Internacionales del Derecho del Trabajo y de la Seguridad Social. Una vision comparada latinoamericana: la libertad sindical

admitiendo que la votación respectiva pueda efectuarse de manera indirecta -y no sólo en forma directa-, no viola los principios de autonomía y libertad sindicales reconocidos en los numerales 123, apartados A, fracción XVI y B, fracción X, constitucional y 3 del Convenio Número 87, relativo a la Libertad Sindical y a la protección al Derecho Sindical, adoptado el 9 de julio de 1948, por la XXXI Conferencia Internacional del Trabajo, en San Francisco, California, porque dicha modalidad de votación se erige como un medio de expresión legítimo y democrático no prohibido por la Constitución para la elección de la directiva sindical que, junto con el método de votación directa, se ofrece a las organizaciones sindicales para que sean ellas quienes determinen libremente el mecanismo que les resulte idóneo en función de sus características, composición territorial y número de afiliados, siempre que éstos tengan asegurada su participación a través del voto libre y secreto ${ }^{35}$.

\subsubsection{Sindicación única. Las leyes o estatutos que la prevén violan la libertad sindical consa- grada en el articulo 123, apartado $B$, fracción $X$, constitucional}

El artículo 123 constitucional consagra la libertad sindical con un sentido pleno de universalidad, partiendo del derecho personal de cada trabajador a asociarse y reconociendo un derecho colectivo, una vez que el sindicato adquiere existencia y personalidad propias. Dicha libertad debe entenderse en sus tres aspectos fundamentales: 1. Un aspecto positivo que consiste en la facultad del trabajador para ingresar a un sindicato ya integrado o constituir uno nuevo; 2 . Un aspecto negativo, que implica la posibilidad de no ingresar a un sindicato determinado y la de no afiliarse a sindicato alguno; y 3 . La libertad de separación o renuncia de formar parte de la asociación. Ahora bien, el mandamiento de un solo sindicato de burócratas por dependencia gubernativa que establezcan las leyes o estatutos laborales, viola la garantía social de libre sindicación de los trabajadores prevista en el artículo 123, apartado B, fracción X, de la Constitución Federal de la República, toda vez que al regular la sindicación única restringe la libertad de asociación de los trabajadores para la defensa de sus intereses ${ }^{36}$.

\subsubsection{Información pública. Tiene ese carácter la que se encuentra en posesión de petróleos} mexicanos y sus organismos subsidiarios relativa a los recursos publicos entregados al sindicato de trabajadores petroleros de la república mexicana por concepto de prestaciones laborales a favor de sus trabajadores

Petróleos Mexicanos y sus organismos subsidiarios (Pemex-Exploración y Producción; Pemex-Refinación; Pemex-Gas y Petroquímica Básica; y Pemex-Petroquímica), constituyen entidades que, conforme a la Ley Federal de Transparencia y Acceso a la Información Pública Gubernamental, están obligadas a proporcionar a los terceros que lo soliciten aquella información que sea

\footnotetext{
35 Tesis Jurisprudencial consultable en: http://200.38.163.178/sjfsist/Paginas/DetalleGeneralV2.aspx?Epoca=le3elfd000000 $00 \&$ Apendice $=100000000000$ \&Expresion $=$ Libertad\%2520Sindical $\&$ Dominio $=$ Rubro,Texto\&TA_TJ $=1 \&$ Orden $=1 \&$ Clase $=$ Det alleTesisBL\&NumTE $=10 \& E p p=50 \& D$ esde $=-100 \& H a s t a=-100 \&$ Index $=0 \&$ InstanciasSeleccionadas $=6,1,2,3,4,5,50,7 \& I D=20066$ $07 \&$ Hit=1 \&IDs $=2006607,2000645,160992,163054,164033,166703,168634,168569,191095,193868 \&$ tipo Tesis=\&Semanario=0\&t $\mathrm{abla}=$

36 Tesis jurisprudencial consultable en: http://200.38.163.178/sjfsist/Paginas/DetalleGeneralV2.aspx?Epoca=1e3e1fd000000 $00 \&$ Apendice $=100000000000 \&$ Expresion $=$ Libertad\%2520Sindical\&Dominio $=$ Rubro, Texto\&TA_TJ $=1 \&$ Orden $=1 \&$ Clase $=$ Det alleTesisBL $\&$ NumTE $=10 \& E p p=50 \& D e s d e=-100 \&$ Hasta $=-100 \&$ Index $=0 \&$ Instancias eleccionadas $=6,1,2,3,4,5,50,7 \& I D=19386$ $8 \&$ Hit=10\&IDs=2006607,2000645,160992,163054,164033,166703,168634,168569,191095,193868\&tipo Tesis=\&Semanario=0\& $t$ abla $=$
} 
pública y de interés general, como es la relativa a los montos y las personas a quienes entreguen, por cualquier motivo, recursos públicos, pues implica la ejecución del presupuesto que les haya sido asignado, respecto del cual, el Director General de ese organismo descentralizado debe rendir cuentas, así como los informes que dichas personas les entreguen sobre el uso y destino de aquéllos; así, los recursos públicos que esos entes entregan al Sindicato de Trabajadores Petroleros de la República Mexicana por concepto de prestaciones laborales contractuales a favor de sus trabajadores, constituyen información pública que puede darse a conocer a los terceros que la soliciten, habida cuenta de que se encuentra directamente vinculada con el patrimonio de los trabajadores aludidos, relativa al pago de prestaciones de índole laboral con recursos públicos presupuestados, respecto de los cuales existe la obligación de rendir cuentas, y no se refiere a datos propios del sindicato o de sus agremiados cuya difusión pudiera afectar su libertad y privacidad como persona jurídica de derecho social, en la medida en que no se refiere a su administración y actividades, o a las cuotas que sus trabajadores afiliados le aportan para el logro de los intereses gremiales ${ }^{37}$.

\subsubsection{Trabajadores de confianza. Son titulares del derecho de libertad sindical consagrado en el artículo 123, apartado A, fracción XVI, de la Constitución politica de los Estados Unidos Mexicanos}

De la interpretación armónica de los artículos 90. y 123, apartado A, fracción XVI, de la Constitución Política de los Estados Unidos Mexicanos, se colige que el derecho a la libertad sindical deriva del derecho fundamental a la libre asociación, y no está limitado a ningún tipo de connacional; su objeto es la defensa de los derechos de los trabajadores, así como el mejoramiento de sus condiciones laborales, a través de la agrupación en un ente con reconocimiento jurídico denominado sindicato; su ejercicio puede estar a cargo de cualquier clase de trabajador por no existir en el texto constitucional exclusión alguna en ese sentido; por tanto, los trabajadores de confianza tienen tutelado, al igual que los de base, el derecho a la libre sindicación, sin ser óbice que sus actividades sean propias de la representación de los intereses de los empleadores, de conformidad con los artículos 9o. y 11 de la Ley Federal del Trabajo, pues ello no les resta identidad como prestadores de un servicio personal subordinado, menos aún les puede limitar el ejercicio del derecho fundamental de libre asociación. Asimismo, atento a los artículos 183 y 184 de la citada ley, los trabajadores de confianza no pueden formar parte de los sindicatos de los demás trabajadores y no pueden beneficiarse de los contratos colectivos de éstos si en su texto existe exclusión expresa en ese sentido; pero ello no puede entenderse como una prohibición a la agrupación sindical por dichos trabajadores, pues obedece únicamente a un propósito de congruencia derivada de la propia naturaleza del trabajador de confianza, identificada por sus funciones con la representación patronal; de modo que implicaría un contrasentido que la defensa de los intereses de los trabajadores de base estuviera sujeta a la opinión y voto de los de confianza, de ahí la prohibición para participar conjuntamente en la vida sindical, mas no impide que los trabajadores de confianza conformen su propio sindicato. Lo anterior tiene sustento en la exposición de motivos de la Ley Federal del Trabajo, publicada en el Diario Oficial de la Federación el 1 de abril de 1970, que dice: "El artículo 183 resuelve las cuestiones relativas a las relaciones entre los trabajadores de confianza y los demás trabajadores: no podrán formar parte de sus sindicatos, lo que no implica que no puedan organizar sindicatos especiales...". Por su parte, los artículos 2, 8, 10 y 11 del Convenio Número 87, relativo

37 Tesis aislada consultable en: http://sjf.scjn.gob.mx/sjfsist/Paginas/DetalleGeneralV2.aspx?ID=2005315\&Clase=DetalleTesi sBL 
Valente Quintana, José Alfonso Aparicio / La efectividad de los derechos y libertades contenidas en las Normas Internacionales del Derecho del Trabajo y de la Seguridad Social. Una visión comparada latinoamericana: la libertad sindical

a la Libertad Sindical y a la Protección al Derecho Sindical, adoptado el 9 de julio de 1948 por la XXXI Conferencia Internacional del Trabajo, en San Francisco California, publicado en el Diario Oficial de la Federación el 16 de octubre de 1950, signado por México, establecen que el derecho a la sindicación no debe hacer distinción alguna de trabajadores y empleadores, siendo compromiso de los Estados adoptantes, no menoscabar el ejercicio de esa garantía en su regulación jurídica interna, por el contrario, adoptar todas las medidas necesarias para asegurarlo ${ }^{38}$.

\subsubsection{Libertad sindical de los trabajadores al servicio del Estado. No abarca el derecho para afiliarse a todos los sindicatos que se constituyan en la dependencia a la que pertenecen, por lo que su baja en uno por pertenecer a otro no viola aquélla}

El Pleno de la Suprema Corte de Justicia de la Nación en la tesis de rubro: "Sindicación única. El artículo 68 de la Ley Federal de los trabajadores al servicio del Estado, viola la libertad sindical consagrada en el artículo 123, apartado B, fracción X, constitucional", declaró la inconstitucionalidad del artículo 68 de la Ley Federal de los Trabajadores al Servicio del Estado, lo que da lugar a que en cada dependencia gubernamental pueden existir más de un sindicato. Asimismo, en el Convenio 87 de la Organización Internacional del Trabajo, suscrito por nuestro país en mil novecientos cincuenta, impone la obligación a los Estados de respetar la decisión de los trabajadores a constituir las organizaciones que estimen pertinentes; y en su artículo 30 . se precisa que las autoridades públicas deberán de abstenerse de toda intervención que limite el derecho o entorpezca el ejercicio legal, para redactar sus estatutos, elegir a sus representantes y organizar su administración y actividades. Por tanto, la garantía de libertad sindical en tratándose de los trabajadores al servicio del Estado, se refiere a su libertad de asociación en el sentido de que pueden afiliarse al sindicato que ellos elijan, no ingresar o separarse de uno y que dentro de cada dependencia gubernamental puede conformarse más de un sindicato. Por otra parte, el artículo 123 constitucional establece la garantía social de la libertad sindical como derecho de los trabajadores, la que en correlación con el contenido de la Ley Federal de los Trabajadores al Servicio del Estado, debe entenderse como la obligación del Estado de respetar la libertad de los trabajadores, profesionales y empresarios, para organizarse en defensa de sus intereses; asimismo, dicha garantía se refiere a que esas organizaciones deben funcionar con verdadera democracia interna sin que el Estado intervenga directa o indirectamente en la designación de sus dirigentes; como la obligación de asegurar la representación auténtica de los agremiados mediante elecciones directas y secretas, sin aceptar presiones políticas o económicas; establecer un sistema objetivo y eficaz para exigir responsabilidades a sus dirigentes y proscribir cualquier tipo de sanciones por razones políticas o ideológicas; además, da derecho a los sindicatos, y en general a todas las organizaciones formadas por razón de ocupación o de trabajo, a actuar en la vida pública para gestionar, frente al Estado y a la opinión pública, las medidas generales o particulares que reclamen el bien común o el interés profesional de sus agremiados y de recomendar las opciones electorales que consideren más convenientes para los mismos, con la limitante de actuar directamente en cuestiones políticas, principalmente

\footnotetext{
38 Tesis Aislada consultable en: http://200.38.163.178/sjfsist/Paginas/DetalleGeneralV2.aspx?Epoca=le3elfd00000000\& Apendice $=1000000000000 \&$ Expresion $=$ Libertad $\% 2520$ sindical $\&$ Dominio $=$ Rubro, Texto \&TA TJ $=0 \& O r d e n=1 \& C l a s e=D e$ talleTesisBL\&NumTE $=47 \&$ Epp $=50 \&$ Desde $=-100 \&$ Hasta $=-100 \&$ Index $=0 \&$ InstanciasSeleccionadas $=6,1,2,3,4,5,50,7 \& \mathrm{ID}=$ 2004349\&Hit=1 \&\&Ds=2007579,2007690,2007826,2006550,2006552,2004933,2004934,2004723,2004724,2004725,200434 $9,2002211,2001957,2001192,2000843,2000634,160295,160294,160293,160292,160291,160290,160289,160288,161744,162$ $028,161962,162551,163093,165923,167159,169632,169586,169585,169584,171911,171910,173996,177145,178186,181846-$ $, 189779,191348,193442,193775,193869,199506 \&$ tipo'Tesis=\&Semanario=0\&tabla $=$
} 
en las electorales, y respetar la libertad y los derechos de sus miembros. Lo anterior da lugar a tres aspectos fundamentales en el derecho sindical de cada trabajador, a saber: 1. Un aspecto positivo, que se traduce en la facultad del trabajador para ingresar a un sindicato ya formado, o de concurrir a la constitución de uno nuevo. 2 . Un aspecto negativo, que implica la posibilidad de no ingresar a un sindicato determinado y la de no afiliarse a ninguno; y, 3. La libertad de separación o renuncia de formar parte de la asociación. No obstante lo anterior, esa libertad no abarca el derecho de los trabajadores para afiliarse a todas las organizaciones sindicales que se constituyan en la dependencia a la que pertenecen; ello, porque la conformación de un sindicato tiene por objeto, entre otros, la defensa de los intereses comunes de los trabajadores que podrían dar margen a conflictos con otras agrupaciones sindicales, para obtener la prioridad en un contrato colectivo de trabajo o cualquier otro diverso del mencionado; o bien, lograr mejoría de alguna otra índole; y por lo mismo, no es admisible que trabajadores miembros de un sindicato, puedan ser a su vez integrantes de otro en una misma dependencia, ya que de aceptarse así, se daría lugar a pugnas inter-gremiales o a choques de intereses encontrados entre esos dos sindicatos, y al mismo tiempo, a que miembros de ambas agrupaciones, estuvieran indistintamente con alguna de ellas, según les conviniera, pues ello rompería con la armonía que debe reinar en dichas agrupaciones, trascendiendo en perjuicio de la finalidad a que se refiere el numeral 356 de la ley laboral ${ }^{39}$.

\subsubsection{Cláusula de exclusión por separación. Los articulos 395 y 413 de la Ley Federal del Trabajo que autorizan, respectivamente, su incorporación en los contratos colectivos de tra- bajo y en los contratos-ley, son violatorios de los artículos 5o., 90. y 123, apartado $A$, frac- ción XVI, de la Constitución Federal}

Los artículos señalados de la Ley Federal del Trabajo que autorizan que en los contratos colectivos de trabajo y en los contratos-ley se incorpore la cláusula de exclusión por separación, lo que permite que el patrón, sin responsabilidad, remueva de su trabajo a la persona que le indique el sindicato que tenga la administración del contrato, por haber renunciado al mismo, transgreden lo dispuesto en el artículo 5o. de la Constitución Política de los Estados Unidos Mexicanos, en cuanto que éste sólo autoriza que puede privarse a una persona de su trabajo lícito por resolución judicial, cuando se afecten derechos de tercero, o por resolución gubernativa, dictada en los términos que señale la ley, cuando se ofendan derechos de la sociedad, supuestos diversos a la privación del trabajo por aplicación de la cláusula de exclusión por separación. Además, también infringen los artículos 9o. y 123, apartado A, fracción XVI, de la propia Carta Magna, de conformidad con los criterios establecidos por el Pleno de la Suprema Corte de Justicia de la Nación en las tesis de jurisprudencia P./J. 28/95 y P./J. 43/99, de rubros: "Cámaras de Comercio e Industria, afiliación obligatoria. El artículo 5o. de la ley en la materia viola la libertad de asociación establecida por el artículo 9o. constitucional" y "Sindicación única. Las leyes o estatutos que la prevén, violan la libertad sindical consagrada en el artículo 123, apartado B, fracción X, constitucional", pues lo dispuesto en los señalados artículos de la Ley Federal del Trabajo es notoriamente contrario a los principios de libertad sindical y de asociación, puesto que resulta contradictorio y, por lo mismo,

\footnotetext{
39 Tesis Aislada consultable en: http://200.38.163.178/sjfsist/Paginas/DetalleGeneralV2.aspx?Epoca=1e3e1fd00000000\&Ape ndice $=100000000000 \&$ Expresion $=$ Sindicaci $\% 25 \mathrm{C} 3 \% 25 \mathrm{~B} 3 \mathrm{n} \% 2520$ unica\&Dominio=Rubro,Texto\&TA_TJ $=2 \&$ Orden $=1 \&$ Clase $=$ Detalle TesisBL\&NumTE $=10 \&$ Epp $=50 \&$ Desde $=-100 \&$ Hasta $=-100 \&$ Index $=0 \&$ IństanciasSeleccionadas $=6,1,2,3,4,5,50,7 \& I D=1$ 62551 \&Hit=3\&IDs=2007826,2002211,162551,171910,178186,189779,193775,193868,193869,199506\&tipoTesis=\&Semanario= 0\&tabla $=$
} 
Valente Quintana, José Alfonso Aparicio / La efectividad de los derechos y libertades contenidas en las Normas Internacionales del Derecho del Trabajo y de la Seguridad Social. Una visión comparada latinoamericana: la libertad sindical

inaceptable jurídicamente, que en la Constitución Federal se establezcan esas garantías, conforme a las cuales, según la interpretación contenida en las referidas jurisprudencias, la persona tiene la libertad de pertenecer a la asociación o sindicato, o bien, de renunciar a ellos y en los mencionados preceptos de la ley secundaria se prevé como consecuencia del ejercicio del derecho a renunciar, la pérdida del trabajo. Finalmente, el hecho de que con el ejercicio de un derecho consagrado constitucionalmente pueda ser separado del trabajo de acuerdo con lo dispuesto en una ley secundaria, que permite introducir en las convenciones colectivas aquella figura, resulta censurable conforme al principio de supremacía constitucional establecido en el artículo 133 de la Ley Fundamental ${ }^{40}$.

\section{CONSIDERACIONES ADICIONALES}

Importante considerar como una fuente internacional, aunque no vinculante, a la Declaración Universal de los Derechos Humanos en su artículo 20, por lo que hace a la Libertad de asociación, pero más en concreto con su artículo número 23 , que se refiere ya directamente a los derechos del trabajador, y en el cual en su punto número cuarto manifiesta que toda persona tiene derecho a fundar sindicatos y a sindicarse para la defensa de sus respectivos intereses.

Este texto destaca la importancia de la "libertad sindical" dejando claro que forma parte de los derechos fundamentales de la humanidad, y no solo eso, sino que marca la pauta para poder poner en manos de los Tribunales Internacionales de Derechos Humanos el conocimiento y resolución a diversos planteamientos que atenten contra dicha libertad.

Cabe destacar también, que desde el año 2009 se ha fundado el Tribunal Internacional de Libertad Sindical en la Ciudad de México, mismo que funciona como tribunal de conciencia, al emitir recomendaciones acerca de las diversas violaciones al principio de "libertad sindical", promovido, como es bien sabido, por la OIT.

Ahora bien, también podemos encontrar que en la Carta de la Organización de Estados Americanos, en su artículo 45 inciso c),el derecho de asociación de empleadores y trabajadores, para la defensa y promoción de sus intereses. Incluyendo el derecho de negociación colectiva y el derecho de huelga por parte de los trabajadores, el reconocimiento de su personalidad jurídica de las asociaciones y la protección de su libertad e independencia.

Este texto anterior, representa la vía idónea para el reconocimiento del derecho de huelga, por lo menos para los países miembros y firmantes de este instrumento vinculatorio. Derecho de huelga que desde hace tiempo ha creado polémica en las reuniones anuales de la OIT, al no estar incorporado al Convenio número 87, y del que se le ha mantenido vinculado a este convenio por medio de criterios jurisprudenciales emitidos por el Comité de Libertad Sindical de la OIT.

La Carta de la Organización de Estados Americanos fue ratificada por México en 1948 y tiene como última reforma el Protocolo de Managua de 1993.

Por último, cabe señalar que también la Convención Americana sobre Derechos Humanos, (Pacto de San José, 1969), ratificada por México en febrero de 1981, hace igualmente referencia al derecho de asociación con fines ideológicos, religiosos, políticos, económicos, laborales y sociales. Derecho de asociación que a nuestra consideración envuelve la protección de la libertad sindical,

10 Tesis jurisprudencial consultable en: http://200.38.163.178/sjfsist/Paginas/DetalleGeneralV2.aspx?Epoca $=1 \mathrm{e} 3 \mathrm{e} 1 \mathrm{fd} 000000$ 00\&Apendice $=1000000000000 \&$ Expresion $=$ Sindicaci $\% 25 \mathrm{C} 3 \% 25 \mathrm{~B} 3 \mathrm{n} \% 2520$ unica\&Dominio $=$ Rubro,Texto\&TA_TJ $=2 \&$ Orden $=$ $1 \&$ Clase $=$ Detalle TesisBL\&NumTE $=10 \& \mathrm{Epp}=50 \&$ Desde $=-100 \&$ Hasta $=-100 \&$ Index $=0 \&$ InstanciasSeleccionadas $=6,1,2,3,4,5,50$, 7\&ID=189779\&Hit=6\&IDs=2007826,2002211,162551,171910,178186,189779,193775,193868,193869,199506\&tipo'Tesis=\&Sem anario $=08$ tabla $=$ 
al reconocer el derecho fundamental para que exista esta (el derecho de asociación), precisada en el ámbito laboral. Parte de la OEA y como parte del sistema regional de protección de derechos humanos coexisten dos organismos de definitiva importancia, por un lado la Comisión Interamericana de Derechos Humanos, así como la Corte Interamericana de Derechos Humanos, con sede en San José Costa Rica, misma en la que ya conocedores del contexto de la Libertad Sindical como Derecho Humano, se podrían someter casos, agotados en las instancias nacionales o por la ineficacia que representaría su agotamiento, ante la jurisdicción de dicha Corte Interamericana de la cual México ha firmado la competencia contenciosa, previo paso por la Comisión Interamericana.

\section{CASO RELEVANTE}

\subsection{Sindicato Nacional de Trabajadores Mineros, Metalúrgicos y Similares de la República Mexicana vs El Gobierno de México}

En México durante los sexenios gobernados por el Partido Acción Nacional (PAN),el 30 de julio del 2007 la mina de Cananea insta ló las banderas de huelga en demanda de mejoras salariales y laborales, así como en apoyo a su dirigente Napoleón Gómez Urrutia. El 11 de enero del año 2008 fueron reprimidos por el gobierno federal después con más de 700 policías que desalojaron a los trabajadores de la mina, basándose en una resolución de la Junta Federal de Conciliación y Arbitraje en la que declaraba la inexistencia de la huelga.

El 14 de febrero de 2008 el Juzgado $13^{\circ}$ de Distrito en materia laboral reconoció a los trabajadores huelguistas la legalidad de su huelga, otorgándoles de esta el amparo y protección de la justicia federal.

Se presume que a finales del año 2005 se celebraron reuniones entre el gobierno federal con la representación patronal de la industria minera, con el propósito de planear una estrategia para desacreditar al SNTMMSRM, así como a su líder, para lo que como parte de esta estrategia se le denunció penalmente ante la Procuraduría General de la Republica por el desvío de recursos de un fideicomiso de cincuenta y cinco millones de dólares constituido entre Industrial Minera México y el sindicato. Esta denuncia fue hecha por parte de un ex integrante del propio sindicato quien había sido expulsado del sindicato un año antes.

Dos días después de que la Secretaría del Trabajo y Previsión Social( STPS) tomara nota de la destitución del líder del sindicato referido, se registró una explosión en la mina de Pasta de Conchos en el Estado de Coahuila, donde murieron 65 mineros, accidente por el cual se evidenciaron varias negligencias por las muy malas condiciones de seguridad e higiene en las que operaba la mina. Hubo actos de violencia cuando las empresas mineras solicitaron la intervención del gobierno de federal para romper las huelgas en las minas. La STPS avaló la inexistencia de la huelga de Cananea.

El desarrollo de todos estos acontecimientos provocó que la Federación Internacional de Trabajadores de la Industria Minera impulsara una protesta en el marco de la Conferencia Internacional del Trabajo, organizado por la OIT, celebrada en Ginebra, Suiza del 31 de mayo al 16 de junio, en la que México podría ser condenado por violar el Convenio número 87 de la OIT.

El Sindicato Minero, así como la FITIM, en la protesta manifestada ante la Conferencia Internacional del Trabajo alegaron la violación del Convenio número 87 por parte de la Dirección General de Registro de Asociaciones de la Secretaría del Trabajo y Previsión Social al registrar de 
manera irregular la supuesta decisión de destituir al Comité Ejecutivo Nacional, así como a su Secretario General en lo particular, y sustituirlo temporalmente negando el ser escuchado al Comité Ejecutivo destituido en su defensa, así como también la manifestación de que el supuesto mal manejo de fondos por el que fue denunciado el líder de este sindicato fue basado en documentación falsa, ocultando un informe de la Comisión Nacional Bancaria y de Valores en el que se acreditaba que no se había cometido este delito.

El Comité de Libertad Sindical después de analizar las quejas del Sindicato Minero y de la FITIM decidió emitir algunas recomendaciones, en las que de primera cuenta se someten a diversas consideraciones, lamentando la toma de nota por la vía administrativa del comité ejecutivo provisional impuesto por el Consejo General de Vigilancia y Justicia, y la consiguiente destitución del comité ejecutivo, y de su secretario general (Napoleón Gómez Urrutia), y estima que la autoridad laboral incurrió en una conducta incompatible con el artículo 3 del Convenio número 87 que consagra el derecho de los trabajadores de elegir libremente a sus representantes.

Asimismo, el Comité deplora la excesiva duración en la tramitación judicial, y pide al Gobierno que tome las medidas pertinentes como lo son reformas legales que garanticen una justicia pronta en relación con el ejercicio de los derechos sindicales.

El Comité también manifiesta constatar que la autoridad laboral resolvió cancelar en vía administrativa el comité ejecutivo sin que fueran oídos y vencidos en juicio los afectados, y que la autoridad laboral asumió sin tener atribuciones para ello la facultad jurisdiccional que la ley laboral expresamente reserva a la Junta de Conciliación y Arbitraje como órgano jurisdiccional.

Por otro lado, el Comité ha sido enterado de la sentencia emitida por el juez penal, en la causa en contra del Secretario General del comité ejecutivo por el delito de administración fraudulenta en la que se niega la orden de aprehensión por no haberse acreditado el cuerpo del delito que se le imputa, lamenta también el conjunto de actos de violencia que se produjeron a causa de la intervención de las fuerzas de seguridad siendo que en situaciones de huelga debe limitarse estrictamente al mantenimiento del orden público ${ }^{41}$.

Las recomendaciones más relevantes, sobre el caso narrado, que emite el Comité de Libertad Sindical, con la aprobación del Consejo de Administración, se mencionan a continuación:

a) El Comité solicita al Gobierno que le mantenga informado acerca de la denuncia penal presentada por el sindicato por falsificación o uso de documentación falsa;

b) Reitera su invitación a una discusión tripartita sobre la oportunidad de acelerar el procedimiento legal de los conflictos inter-sindicales;

c) El Comité pide al gobierno le informe del resultado de los recursos presentados por el sindicato contra la decisión de la Junta Federal de Conciliación y Arbitraje de declarar la titularidad de los contratos colectivos;

d) Solicita al Gobierno información sobre la situación del congelamiento de las cuentas bancarias del sindicato;

e) Se le solicita al Gobierno se le comunique el resultado de los procesos relativos a los actos de violencia contra sindicalistas.

Como vemos la situación acontecida en México en el sector minero originó un conflicto de suma importancia a nivel nacional que trascendió fronteras y se expuso internacionalmente en la Conferencia Internacional del Trabajo, en la que el Comité de Libertad Sindical tuvo a bien hacer diversas recomendaciones con el afán de velar por el respeto de la Libertad Sindical, incluso

${ }_{41}$ Cfr.: http://noticiasmx.terra.com.mx/terramagazine/interna/0,,OI2473640-EI8864,00 Conflicto+minero+en+Mexico+una+ historia+abierta.html 
Valente Quintana, José Alfonso Aparicio / La efectividad de los derechos y libertades contenidas en las Normas Internacionales del Derecho del Trabajo y de la Seguridad Social. Una visión comparada latinoamericana: la libertad sindical

recomendando al gobierno mexicano el tomar las medidas en forma de reformas de la Ley Federal del Trabajo, que permita un mejor desarrollo del procedimiento legal en conflictos colectivos de trabajo $^{42}$.

\section{CONCLUSIONES}

Los obstáculos que encuentra la libertad sindical para su vida, creemos que han quedado evidenciados con suficiencia alrededor del presente texto. A manera de conclusión y resumen, podríamos afirmar que la Libertad Sindical encuentracon diversos obstáculos, entre los que destacamos los siguientes:

1. El registro sindical. Con obstáculos formales y de hecho para que se otorgue éste y en el carácter constitutivo de la organización sindical que tiene el registro sindical;

2. Autonomía. La carencia de la autonomía que viven las organizaciones sindicales, que han sido reducidas a instancias de gestión de condiciones laborales;

3. En el secreto con que se llevan los Contratos Colectivos por parte de todas las autoridades del trabajo negándose el conocimiento incluso a los propios trabajadores que ignoran en muchos casos aún el nombre de la organización sindical que los representa;

4. La aún no obligatoriedad para México del Convenio 98.

Obstáculos evidentes que dejan implícitos algunos de los temas pendientes para que la libertad sindical en México sea una realidad.

\section{BIBLIOGRAFÍA}

Beaudonnet, Xavier (2009): Derecho Internacional del Trabajo y Derecho Interno. (Turín, Centro Internacional de Información de la OIT)

Bouzas Ortíz, Alfonso; Mendoza Mondragón, Ruth (1999): "Democracia sindical en la globalización: enfoque teórico, realidad y propuesta", en: Bouzas Ortíz, José Alfonso (coordinador), Libertad Sindical. (México, UNAM-FAT-UAM-AFL)

BurgoA, Ignacio (1984): Garantías Individuales. (México, Porrúa, décimooctava edición)

De Buen, Néstor (2011): "La autonomía sindical, el registro de los sindicatos en México y otras trampas novedosas", Revista Latinoamericana de Derecho Social, $\mathrm{N}^{\circ} 13$.

De la Cueva, Mario (1979): El Nuevo Derecho Mexicano del Trabajo. (México, Editorial Porrúa).

De la Cueva, Mario (1992): El Nuevo Derecho Mexicano del Trabajo. (México, Editorial Porrúa, sexta edición).

Fix-Zamudio, Héctor (2006): "Protección jurídico constitucional de los derechos humanos de fuente internacional en los ordenamientos de Latinoamérica”, en: PÉREZ-Rovo, Javier et al. (coordinadores), Derecho constitucional para el siglo XXI. Actas del Vlll Congreso Iberoamericano de Derecho Constitucional. (Pamplona, Thompson Aranzadi), t. ll, pp. 1727-1746.

Lastra Lastra, José Manuel (2000): "La libertad sindical", Boletin Mexicano de Derecho Comparado, № 98.

Russomano, Mozart V. (1977): Principios Generales de derecho sindical. (Madrid, Instituto de Estudios Políticos)

SánCheZ-CastañedA, Alfredo (2002): "Hacia una definición de los derechos fundamentales en el trabajo y su exigibilidad", en: Ferrer Mac-Gregor, Eduardo; Zaldivar Lelo de Larrea, Arturo (coordinadores), la ciencia del derecho procesal constitucional. Estudios en homenaje a Héctor Fix-Zamudio en sus cincuenta años como investigador del derecho. (México, UNAM-Instituto Mexicano de Derecho Procesal Constitucional-Marcial Pons), t. XII.

${ }^{42}$ Cfr. http://sindicatomineromexicano.blogspot.mx/ 
Valente Quintana, José Alfonso Aparicio / La efectividad de los derechos y libertades contenidas en las Normas Internacionales del Derecho del Trabajo y de la Seguridad Social. Una visión comparada latinoamericana: la libertad sindical

SÁNCHEZ-CASTAÑEDA, Alfredo (2002): "La cláusula de exclusión y el pluralismo sindical en el derecho comparado", en Kunczyn, Patricia; Macías Vázquez María Carmen (coordinadores), Libertad sindical: cláusula de exclusión (México, Instituto de Investigaciones Jurídicas-UNAM)

Sánchez-Castañeda, Alfredo; Reynoso Castillo, Carlos (2013): La Nueva Legislación Laboral Mexicana. (México, Instituto de Investigaciones Jurídicas-UNAM)

Toledano, Vicente (1926): La libertad sindical en México. (México, Universidad Obrera).

Trueba Urbina, Alberto; Trueba Barrera, Jorge (2008): Ley Federal del Trabajo Comentarios, Prontuario, Jurisprudencia y Bibliografia. (México, Editorial Porrúa, ochentayochoava edición).

\section{JURISPRUDENCIA JUDICIAL}

- Tesis Jurisprudencial consultable en: http://200.38.163.178/sjfsist/Paginas/DetalleGeneralV2.aspx?id=161163\&Cl ase $=$ Detalle TesisBL

-TesisJurisprudencial consultableen:http:/200.38.163.178/sjfsist/Paginas/DetalleGeneralV2.aspx:Epoca=1e3elfd00000000\&A pendice $=1000000000000 \&$ Expresion=L_ibertad $\% 2520$ Sindical $\&$ Dominio=Rubro, Texto\&TA T] $=1 \&$ Orden $=1 \&$ Clase $=$ DetalleTesisBL\&NumTE=108Epp=50\&Desde=-100\&Hasta=-100\&Index=0\&InstanciasSeleccionadas=6,1,2,3,4,5,50,7 \&ID=2006607\&Hit=1\&IDs=2006607,2000645,160992,163054,164033,166703,168634,168569,191095,193868\&ti poTesis $=\&$ Semanario $=0 \&$ tabla $=$

-Tesisjurisprudencial consultableen:http://200.38.163.178/sjfsist/Paginas/DetalleGeneralV2.aspx?Epoca=1e3elfd00000000\&A pendice=1000000000000\&Expresion=Libertad\%2520Sindical\&Dominio=Rubro,Texto\&TA_T]=1\&Orden=1\&Clase= DetalleTesisBL\&NumTE=10\&Epp=50\&Desde=-100\&Hasta=-100\&Index=0\&InstanciasSeleccionadas=6,1,2,3,4,5,50,7 \&ID=193868\&Hit=10\&IDs=2006607,2000645,160992,163054,164033,166703,168634,168569,191095,193868\&ti poTesis $=\&$ Semanario $=0 \&$ tabla $=$

- Tesis aislada consultable en: http://sjf.scjn.gob.mx/sjfsist/Paginas/DetalleGeneralV2.aspx?ID=2005315\&Clase=De talleTesisBL

- Tesis Aislada consultable en: http://200.38.163.178/sffsist/Paginas/DetalleGeneralV2.aspx?Epoca=1 e3e1fd000000 00\&Apendice $=1000000000000 \&$ Expresion $=$ Libertad\%2520 sindical $\&$ Dominio $=$ Rubro, Texto\&TA_TJ $=0$ \&Orden $=1 \&$ Clase $=$ DetalleTesisBL \&NumTE $=47 \& E p p=50 \&$ Desde $=-100 \&$ Hasta $=-100 \&$ Index $=0 \&$ Instanc iasSeleccionadas $=6,1,2,3,4,5,50,7 \& \mathrm{ID}=2004349 \& \mathrm{Hit}=11 \& \mathrm{ID} s=2007579,2007690,2007826,2006550,20$ $06552,2004933,2004934,2004723,2004724,2004725,2004349,2002211,2001957,2001192,2000843,20$ $00634,160295,160294,160293,160292,160291,160290,160289,160288,161744,162028,161962,162551$ $, 163093,165923,167159,169632,169586,169585,169584,171911,171910,173996,177145,178186,1818$ $46,189779,191348,193442,193775,193869,199506 \&$ tipo Tesis=\&Semanario=0\&tabla $=$

- Tesis Aislada consultable en: hrtp://200.38.163.178/sjsist/Paginas/DetalleGeneralV2.aspx'Epoca=1e3el fd00000000\&Apendice= $1000000000000 \&$ Expresion=Sindicaci\%25C3\%25B3n\%2520unica\&Dominio=Rubro,Texto\&TA_TJ=2\&Orden=1\&C lase $=$ DetalleTesisBL\&NumTE $=10 \& E p p=50 \&$ Desde $=-100 \&$ Hasta $=-100 \& I n d e x=0 \&$ InstanciasSeleccionadas $=6,1,2,3,4,5,5$ 0,7\&ID=162551\&Hit=3\&IDs=2007826,2002211,162551,171910,178186,189779,193775,193868,193869,199506\&षi poTesis $=\&$ Semanario $=0 \&$ tabla $=$

- Tesis jurisprudencial consultable en: http://200.38.163.178/s/fsis/Paginas/DetalleGeneralV2.aspx:Epoca=1e3elfd00000000\&Ape ndice= $1000000000000 \&$ Expresion=Sindicac\% $25 \mathrm{C} 3 \% 25 \mathrm{~B} 3 n \% 2520$ unica\&Dominio=Rubro,Texto\&TA_TJ $=2 \&$ Orden=1 $\&$ Clase-DetalleTerisBL\&NumTE $=10 \& \mathrm{Epp}=50 \&$ Desde $=-100 \&$ Hasta $=-100 \& I n d e x=0 \&$ InstanciasSeleccionadas $=6,1,2,3,4,5$ ,50,7\&ID=189779\&Hit=6\&IDs=2007826,2002211,162551,171910,178186,189779,193775,193868,193869,199506\&ti poTesis $=\&$ Semanario $=0 \&$ tabla $=$

\section{NORMAS CITADAS}

DOF de fecha 17/06/14. Disponible en: http://dof.gob.mx/nota_detalle.php?codigo $=5348865 \&$ fecha $=17 / 06 / 2014$

DOF defecha 30/11/12. Disponible en: http://www.dof.gob.mx/nota_detalle.php?codigo=5280815\&fecha=30/11/2012 